\title{
Effects of Birth-Related Events on Central Blood Flow Patterns
}

\author{
DAVID F. TEITEL, HARRIET S. IWAMOTO, AND ABRAHAM M. RUDOLPH \\ Cardiovascular Research Institute and the Departments of Pediatrics, Physiology, and Obstetrics and \\ Reproductive Sciences, University of California, San Francisco, California 94143
}

\begin{abstract}
We determined the effects of three components of the birth process on central blood flow patterns in fetal sheep. We instrumented 16 fetal sheep at $133.0 \pm$ 1.2 days gestation, inserting various intravascular catheters, intubating the trachea, and placing an inflatable balloon around the umbilical cord. After 2-3 days, we determined central blood flow patterns using radionuclidelabeled microspheres under control conditions, during positive pressure ventilation without oxygenation, during ventilation with $100 \% \mathrm{O}_{2}$, and after umbilical cord occlusion. The foramen ovale right to left shunt was essentially abolished, decreasing from $102 \pm 48$ to $66 \pm 40 \mathrm{ml} / \mathrm{min} /$ $\mathrm{kg}$ with ventilation, and to only $13 \pm 10 \mathrm{ml} / \mathrm{min} / \mathrm{kg}$ with oxygenation. The ductus arteriosus right to left shunt decreased progressively, from a control level of $224 \pm 64$ to $6 \pm 10 \mathrm{ml} / \mathrm{min} / \mathrm{kg}$ after umbilical cord occlusion. A ductus arteriosus left to right shunt appeared with oxygenation $(41 \pm 26 \mathrm{ml} / \mathrm{min} / \mathrm{kg})$ and increased to $65 \pm 43 \mathrm{ml} /$ $\mathrm{min} / \mathrm{kg}$ after cord occlusion. Left ventricular output increased progressively as a percentage of combined ventricular output (from a control value of 34.8 to $59.5 \%$ after cord occlusion), and increased absolutely with ventilation (from $134 \pm 44$ to $211 \pm 87 \mathrm{ml} / \mathrm{min} / \mathrm{kg}$ ). However, right ventricular output decreased (from a control value of 258 \pm 75 to $144 \pm 36 \mathrm{ml} / \mathrm{min} / \mathrm{kg}$ after cord occlusion) so that combined ventricular output did not change. Although the transition from the fetal to neonatal circulatory pattern was accomplished by simulating these three components of the birth process, none is alone responsible for the large increase in combined ventricular output normally seen at birth. (Pediatr Res 22: 557-566, 1987)
\end{abstract}

Abbreviation

CVO, combined ventricular output

The adaptation of the fetus to extrauterine life involves numerous processes that occur rapidly. Paramount among these is the change in the pattern of circulation of blood. The fetal circulation is characterized by the presence of central shunts that direct systemic venous return to the systemic arterial circulation (Fig. 1): the foramen ovale directs the more highly oxygenated umbilical venous blood from the right atrium to the left heart to supply oxygen to the heart, brain, and other organs, and the ductus arteriosus directs the less oxygenated right ventricular output via the descending aorta to the placenta for oxygen

Received September 10, 1986; accepted June 30, 1987

Correspondence and reprint requests David F. Teitel, M.D., Room M1327 Box 0130, University of California, San Francisco, San Francisco, CA 94143.

Supported by an NIH Program Project Grant HL 24056 and NIH Research Grant HL 35842. uptake. The right ventricle ejects about $50 \%$ more blood than the left ventricle in the sheep fetus (1). As part of the transition from fetal to neonatal life, these central blood flow patterns change abruptly. The right to left shunts through the foramen ovale (2) and through the ductus arteriosus (3) cease rapidly, and a transient left to right shunt occurs until the ductus arteriosus closes fully within a few hours after birth $(3,4)$. The two ventricles eject the same volumes once the ductus arteriosus does close. Associated with the increased oxygen requirements after birth, left ventricular output increases 2 - to $2 \frac{1}{2}$-fold $(5,6)$.

The specific factors that cause this dramatic change in central blood flow patterns and their timing are not known, because birth involves several processes that occur almost simultaneously. Labor, delivery, rhythmic gaseous expansion of the lung (ventilation), increased oxygenation, umbilical cord clamping, and decreased environmental temperature are all components of the birth process and each may individually or in concert affect the circulation. Previous studies either have compared fetal measurements with those obtained postnatally after the entire birth process has been completed (6), or have been performed on acutely exteriorized, open-chest sheep fetuses $(2,7-9)$, in which cardiovascular responses may be greatly altered (10). A recent study has investigated the in utero effects of oxygen ventilation on left ventricular output in fetal sheep (11), but the effects of ventilation prior to oxygenation and of umbilical cord occlusion were not studied, nor were the changes in right ventricular output and blood flow through the central shunts.

We undertook the present study to determine the sequential effects of three important components of the birth process: ventilation, oxygenation, and umbilical cord occlusion, on the central blood flow patterns in the near-term sheep fetus. We studied chronically instrumented fetuses in utero so that the sequential effects of each component could be determined without the influence of anesthesia or exteriorization. We defined the hemodynamic adjustments that are induced by each of these processes and the subsequent effects that these adjustments have on the central circulation.

\section{MATERIALS AND METHODS}

Animals. Sixteen fetal sheep between 133 and 137 days gestation (mean of 135.1 days) were studied $48-72 \mathrm{~h}$ after surgery was completed (performed at $133.0 \pm 1.2$ days gestation). The fetuses were of normal weight $(3.55 \pm 0.56 \mathrm{~kg})$ and had normal blood gases (Table 1) and hemoglobin concentrations $(10.9 \pm 1.6 \mathrm{~g} / \mathrm{dl}$ ) at the onset of the study.

Surgery. The ewe was fasted for 24 to $48 \mathrm{~h}$ prior to surgery. Spinal or low epidural anesthesia was achieved with $4 \mathrm{ml}$ of $1 \%$ tetracaine hydrochloride (Pontacaine $\mathrm{HCl}$, Breon Laboratories, New York, NY), and polyvinyl catheters were inserted in a pedal artery and vein for blood sampling and infusion of $10 \%$ dextrose in $0.9 \%$ saline during the surgery. During surgery, $50-100 \mathrm{mg}$ of ketamine hydrochloride (Vetalar, Parke-Davis, Morris Plains, 
$\mathrm{NJ}$ ) was administered intravenously to the ewe every 10-15 min, and $0.25 \%$ lidocaine hydrochloride (Xylocaine, Astra Pharmaceutical Products Inc., Westborough, MA) was administered locally to the fetus, for additional anesthesia.

A midline incision was made in the ventral abdomen and the pregnant horn of the uterus was exposed. A fetal hindlimb was exposed through a small incision in the uterus, and polyvinyl catheters were placed in the pedal artery and vein and advanced to the descending aorta and abdominal inferior vena cava respectively. A $12 \mathrm{~F}$ polyvinyl catheter was placed in the amniotic cavity and a multiple side-hole catheter was placed in the umbilical vein after exposure of the allantoic sac. The skin and uterine incisions were then closed. Through a separate uterine incision, the left chest of the fetus was exteriorized and a left lateral thoracotomy was performed in the fourth intercostal space. Succinylcholine hydrochloride (Burroughs-Wellcome Co., Research Triangle Park, NC), in a single dose of $5 \mathrm{mg}$, was administered intravenously upon exposure of the upper body because, despite the anesthesia, fetal breathing can occur when the face is exposed to air: inspiration of any air into the alveoli may induce irreversible processes in the lungs that normally occur at birth and which would invalidate our subsequent study of ventilation. A polyvinyl catheter was placed in the internal thoracic artery and advanced to the ascending aorta or brachiocephalic trunk. The pericardium was then opened and Teflon-tipped polyvinyl catheters were inserted in the left atrium and main pulmonary artery using a special needle-cannula assembly (12). An $8 \mathrm{~F}$ polyvinyl catheter was placed in the pleural cavity to drain any

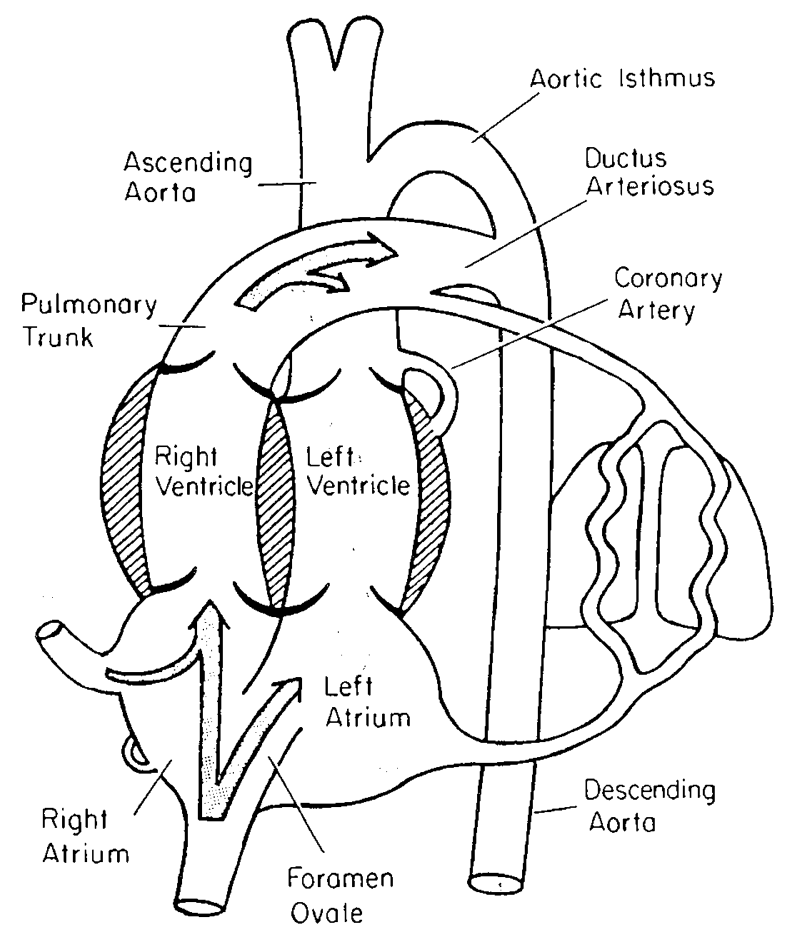

Fig. 1. Diagramatic representation of the fetal circulation. Arrows denote direction of blood flow through the heart and central blood vessels. fluid that may accumulate postoperatively and for drainage of a potential left-sided pneumothorax during subsequent ventilation. The chest was closed in layers. The fetal neck was then exposed through the same uterine incision and the trachea was dissected. It was ligated proximally and a $4.5 \mathrm{~mm}$ ID tracheal tube was advanced just beyond the level of the clavicle. The tube was attached to two $100-\mathrm{cm}$ lengths of $12 \mathrm{~F}$ polyvinyl tubing using a $\mathrm{Y}$ connector and all tubes were filled with $0.9 \% \mathrm{NaCl}$ solution. One tube was sealed to prevent loss of tracheal fluid, and the other was connected to the $12 \mathrm{~F}$ tubing that was placed in the amniotic cavity, to allow tracheal fluid to drain into the amniotic cavity. The skin incision was closed. The umbilical cord was then located at the umbilical ring and a silicone rubber cuff with an inflatable balloon was placed around the cord just distal to the abdomen. Antibiotics $(600 \mathrm{mg}$ of kanamycin sulfate, Bristol Laboratories, Syracuse NY, and 1 million $U$ of penicillin $G$ potassium, E.R. Squibb \& Sons Inc., Princeton, NJ) were instilled in the amniotic cavity and $0.9 \%$ warmed saline was added to replace loss of amniotic fluid. The uterine incision was closed. All vascular catheters were filled with heparin sodium (1000 U/ ml, Organon Inc., West Orange, NJ) and sealed. All catheters and tubing were exteriorized to the left flank of the ewe and protected by a cloth pocket sutured to the skin. The abdominal incision was closed in layers and the ewe was allowed to recover. Antibiotics $(600 \mathrm{mg}$ of kanamycin sulfate and 1 million $U$ of penicillin $\mathrm{G}$ potassium) were administered intravenously to the ewe and into the amniotic cavity daily.

Experimental protocol. Four conditions were studied in the following sequence: 1) control, 2) ventilation using a gas mixture with $\mathrm{pO}_{2}$ and $\mathrm{pCO}_{2}$ levels equivalent to those in fetal arterial blood, to determine the effects of rhythmic gaseous distension of the lung without oxygenation, 3) ventilation with $100 \%$ oxygen (oxygenation), and 4) umbilical cord occlusion during ventilation with $100 \%$ oxygen. The same study protocol was followed in all conditions, and is described in "Control period."

Control period. The ewe was placed in a study cage and allowed free access to alfalfa pellets and water. Fetal blood samples were obtained from the ascending aorta for determination of blood gases and $\mathrm{pH}$, (Corning $158 \mathrm{pH} /$ blood gas analyzer, Medfield, $\mathrm{MA}$ ), and hemoglobin concentration and oxygen saturation (Radiometer OSM2 hemoximeter, Copenhagen, Denmark). Combined ventricular output and blood flow distribution were then determined by the radionuclide-labeled microsphere technique. Two differently labeled $15-\mu$ microspheres (selected from ${ }^{57} \mathrm{Co}$, ${ }^{51} \mathrm{Cr},{ }^{153} \mathrm{Gd},{ }^{114} \mathrm{In},{ }^{54} \mathrm{Mn},{ }^{95} \mathrm{Nb},{ }^{113} \mathrm{Sn},{ }^{85} \mathrm{Sr}$, or ${ }^{65} \mathrm{Zn}$ ) were injected. In all instances microspheres were injected into the inferior vena cava. In the first few studies, a second set of microspheres were also injected into the umbilical vein, but this site was changed to the left atrium when it became apparent that inadequate microspheres were crossing the foramen ovale to the left heart during oxygenation for calculation of systemic blood flow. Reference blood samples were withdrawn at a rate of about $4 \mathrm{ml} / \mathrm{min}$ from the ascending aorta, descending aorta, and pulmonary artery, beginning immediately prior to the injection of microspheres and continuing for at least $40 \mathrm{~s}$ after the injection had been completed. The total volume of blood removed for sampling was calculated and an equal volume of fetal blood (or maternal blood, if fetal blood was not available) was infused after the microsphere study.

Ventilation. The two polyvinyl tubes connected to the tracheal

Table 1. Femoral arterial blood gases (mean $\pm 1 S D)^{*}$

\begin{tabular}{lcccc}
\hline & Control & Ventilation & Oxygenation & Cord occlusion \\
\hline$n$ & 16 & 16 & 16 & 12 \\
$\mathrm{pH}$ & $7.38 \pm 0.06$ & $7.34 \pm 0.07$ & $7.33 \pm 0.08$ & $7.30 \pm 0.14$ \\
$\mathrm{pO}_{2}(\mathrm{~mm} \mathrm{Hg})$ & $18.0 \pm 3.0$ & $19.1 \pm 3.5$ & $142.4 \pm 127.5^{*}$ & $179.8 \pm 140.7$ \\
$\mathrm{pCO}_{2}(\mathrm{~mm} \mathrm{Hg})$ & $53.1 \pm 6.1$ & $53.1 \pm 7.7$ & $50.6 \pm 8.4$ & $59.8 \pm 20.7$ \\
\hline
\end{tabular}

\footnotetext{
* Significantly different from the condition immediately preceding it, $p \leq 0.05$.
} 
tube were then opened and the tracheal fluid was allowed to drain. A mixture of nitrogen, oxygen, and carbon dioxide was balanced to match the concentrations of oxygen and carbon dioxide in the descending aortic blood determined during the control study. The gas mixture was comprised of approximately $92 \%$ nitrogen, $3 \%$ oxygen, and $5 \%$ carbon dioxide, but varied between fetuses depending on their control blood gases. The gas was briefly allowed to flow through the polyvinyl tubing at a rate of about $10 \mathrm{liter} / \mathrm{min}$ so that the fetus would not be exposed to high concentrations of oxygen at the onset of ventilation. The tubing was then connected to a specially designed pump which had an adjustable inspiratory popoff valve proximal to the tracheal tube, a solenoid immediately distal to the tracheal tube, and an adjustable expiratory valve distal to the solenoid. The solenoid was intermittently closed to allow gas to enter the tracheal tube and ventilate the fetal lung, and the inspiratory:expiratory time ratio was about $0.8: 1$. By adjusting the inspiratory and expiratory valves, inspiratory and end-expiratory pressures could be regulated without changing the flow rate of the gas mixture. Expired gases of the fetus were washed out of the system during expiration by the continuous flow of gases so that rebreathing would not occur. Tracheal pressures (fluid filled tube in the distal tracheal tube connected to Statham P23Db pressure transducers, Statham Instruments, Oxnard, CA) were measured in 15 fetuses and tidal volume (Fleisch type no. 00 pneumotacograph, Medical Inc., Richmond, VA, Validyne model DP45-16 pressure transducer and CD 15 carrier demodulator. Validyne Engineering Corporation, Northridge, CA) was measured in nine fetuses (Table 2). The ventilation settings were initially adjusted to deliver a tidal volume of about $20-30 \mathrm{ml}$, similar to that used in newborn lambs (13) and humans (14). As the lungs became more compliant throughout the study, minor adjustments were made in the ventilation settings. Ventilation without altering fetal blood gases (Table 1) was continued for 15 min. The study protocol was then performed as described in the "Control period."

Oxygenation. The gas mixture was then changed to $100 \%$ oxygen and ventilation was continued for another $15 \mathrm{~min}$. The study protocol was repeated. Carbon dioxide was not added to the oxygen because its addition was initially associated with an increase in $\mathrm{pCO}_{2}$. This was probably caused by the fall in placental blood flow during oxygenation, which probably resulted in inadequate removal of carbon dioxide produced by the fetus.

Umbilical cord occlusion. The balloon around the umbilical cord was fully inflated to completely occlude the umbilical vessels. Complete occlusion was substantiated by the absence of significant blood flow to the placenta (see "Results"). After 15 min, the study protocol was repeated. In four of the 16 fetuses, cord occlusion could not be studied, because of a faulty balloon

Table 2. Ventilatory settings during ventilation, oxygenation, and after umbilical cord occlusion; pressures are referenced to amniotic pressure (mean $\pm 1 S D)^{*}$

\begin{tabular}{lccc}
\hline & Ventilation & Oxygenation & Cord occlusion \\
\hline$n$ & 15 & 14 & 12 \\
$\begin{array}{l}\text { Peak inspiratory } \\
\text { pressure (mm }\end{array}$ & $26.5 \pm 10.1$ & $26.0 \pm 8.8$ & $24.5 \pm 8.9$ \\
$\quad \begin{array}{l}\text { Hg) } \\
\text { Positive end-expir- } \\
\text { atory pressure } \\
\quad(\mathrm{mm} \mathrm{Hg})\end{array}$ & $3.3 \pm 6.3$ & $4.1 \pm 5.9$ & $3.7 \pm 6.2$ \\
$\begin{array}{l}\text { Ventilatory rate } \\
(/ \mathrm{min})\end{array}$ & $50.1 \pm 7.8$ & $57.2 \pm 12.2$ & $56.7 \pm 13.7$ \\
$n \quad$ & 9 & 9 & 9 \\
Tidal volume (ml) & $23.3 \pm 14.6$ & $35.4 \pm 15.9$ & $30.7 \pm 10.4$ \\
\hline
\end{tabular}

* No significant differences were noted between variables in any condition and the condition immediately preceding it. in two and the development of pneumothoraces with cardiovascular decompensation in two.

Upon completion of the study the umbilical cord balloon was deflated and ventilation was discontinued. The ewe was killed with large doses of pentobarbital sodium (Euthanasia-6, Veterinary Laboratories, Lenexa, KS) and the fetus was removed from the uterus. The carcass was divided into upper and lower segments at the second intercostal space. Individual fetal organs, body segments, and the placenta were dissected, weighed, and placed in formalin. The tissues were carbonized in an oven, ground into a coarse powder, and placed in plastic vials to a uniform height of $3 \mathrm{~cm}$. Radioactivity of each tissue and reference blood sample was counted in a 1000-channel multichannel pulse-height analyzer (Norland, Fort Atkinson, WI). Specific activity of each isotope within a sample was calculated by the least-squares method (15).

Calculations. During the control period, a large quantity of blood flows through the foramen ovale from the right to the left atrium and the flow through the ductus arteriosus is entirely from right to left. Adequate numbers of microspheres can thus pass from the inferior vena cava or umbilical vein to the upper and lower bodies for calculation of organ blood flows, and pulmonary blood flow can be calculated using the pulmonary artery reference sample and the radioactivity count in the lungs. This technique only calculates the right ventricular contribution to lung flow, excluding bronchial flow. The calculation of ventricular outputs and central shunts uses the method of Heymann et al. (1) and is presented in Appendix 1.

Upon ventilation, pulmonary vascular resistance falls and blood flow dramatically increases. This increases the volume of pulmonary venous blood returning to the left atrium and decreases the right to left shunt through the foramen ovale and the ductus arteriosus. Thus, microspheres injected into the inferior vena cava or umbilical vein may not cross in sufficient quantity to calculate fetal body blood flows. In addition, the presence of a left to right shunt across the ductus arteriosus distal to the main pulmonary artery reference catheter invalidates the calculation of pulmonary blood flow. We therefore injected microspheres of different labels into the inferior vena cava and left atrium and calculated organ blood flows, ventricular outputs, and flow through central shunts using the method described in Appendix 2. Using this method, both the right and left ventricular contributions to lung flow are calculated. The left ventricular contribution during the control period represents bronchial flow only, because there is no left to right shunt through the ductus arteriosus in the normal fetus. In the last six fetuses we injected microspheres into both the left atrium and inferior vena cava during the control period and thus were able to calculate bronchial flow as the difference in the two methods of calculating lung flow. We found that bronchial flow was small (less than $2 \%$ of combined ventricular output in four of six and less than $3 \%$ in all six fetuses); we corrected the calculation of the left to right shunt through the ductus arteriosus accordingly (Fig. 4). In one animal, there was inadequate mixing of microspheres in the heart and this animal was excluded from the analysis.

Analysis. We studied the sequential effects of ventilation, oxygenation, and umbilical cord occlusion in this protocol. Determination of their independent effects is not possible because the order of the interventions cannot be randomized. Oxygenation of the fetal lung cannot precede ventilation alone without inducing multiple and probably irreversible metabolic and hemodynamic consequences, and the umbilical cord cannot be occluded prior to oxygenation. This protocol can thus be divided into three distinct experiments, each determining the effects of an intervention on the previous condition. Data from each of these experiments were analyzed using paired $t$ tests, comparing only that data obtained during one condition with that obtained during the condition immediately preceding it. For hemodynamic and ventilation data, statistical significance was considered present when the $p$ value was $\leq 0.05$. For microsphere data, 
because of the large number of organ and regional flows calculated, statistical significance was considered present when the $p$ value was $\leq 0.01$.

\section{RESULTS}

Central blood flow patterns. Control Period. The distribution of CVO was very similar to that previously described $(1,16)$ in near-term fetal sheep. The flows, as percentages of CVO, are presented in Figure 2. The right ventricle ejected $258 \pm 69 \mathrm{ml} /$ $\mathrm{min} / \mathrm{kg}$, of which $224 \mathrm{ml} / \mathrm{min} / \mathrm{kg}$ passed through the ductus arteriosus to the lower body and placenta, and the remainder (31 $\pm 18 \mathrm{ml} / \mathrm{min} / \mathrm{kg}$ ) went to the lungs. The left ventricle ejected only $134 \pm 44 \mathrm{ml} / \mathrm{min} / \mathrm{kg}$, about one-half of the output of the right ventricle. The majority of left ventricular output perfused the heart, brain, and upper body $(101 \pm 21 \mathrm{ml} / \mathrm{min} / \mathrm{kg})$ and the remainder $(44 \pm 53 \mathrm{ml} / \mathrm{min} / \mathrm{kg}$ ) crossed the aortic isthmus to the descending aorta. About two-thirds of CVO thus supplied the lower body $(122 \pm 35 \mathrm{ml} / \mathrm{min} / \mathrm{kg})$ and placenta $(138 \pm 48$ $\mathrm{ml} / \mathrm{min} / \mathrm{kg}$ ) and returned via the inferior vena cava to the right atrium. More than one-third of the inferior vena caval return crossed the foramen ovale to the left atrium $(102 \pm 48 \mathrm{ml} / \mathrm{min} /$ $\mathrm{kg}$ ). A comparison of values for ventricular outputs and flows through the foramen ovale and ductus arteriosus among the four conditions are presented in Figures 3 and 4.

Ventilation. Ventilation with the gas mixture which did not change fetal arterial blood gases caused major changes in the distribution of CVO (Fig. 5). The right ventricle ejected $225 \pm$ $69 \mathrm{ml} / \mathrm{min} / \mathrm{kg}$, barely more than one-half of CVO. Less than one-half of its output $(96 \pm 55 \mathrm{ml} / \mathrm{min} / \mathrm{kg})$ now passed through the ductus arteriosus to the descending aorta, the large remainder perfusing the lungs. There was a large but variable increase in pulmonary blood flow (from $31 \pm 19 \mathrm{ml} / \mathrm{min} / \mathrm{kg}$ during control to $145 \pm 95 \mathrm{ml} / \mathrm{min} / \mathrm{kg}$ ). The left ventricle ejected significantly more blood $(211 \pm 87 \mathrm{ml} / \mathrm{min} / \mathrm{kg})$ than during control, and the majority of this increase was directed across the aortic isthmus to the descending aorta $(133 \pm 84 \mathrm{ml} / \mathrm{min} / \mathrm{kg})$. Blood flow to

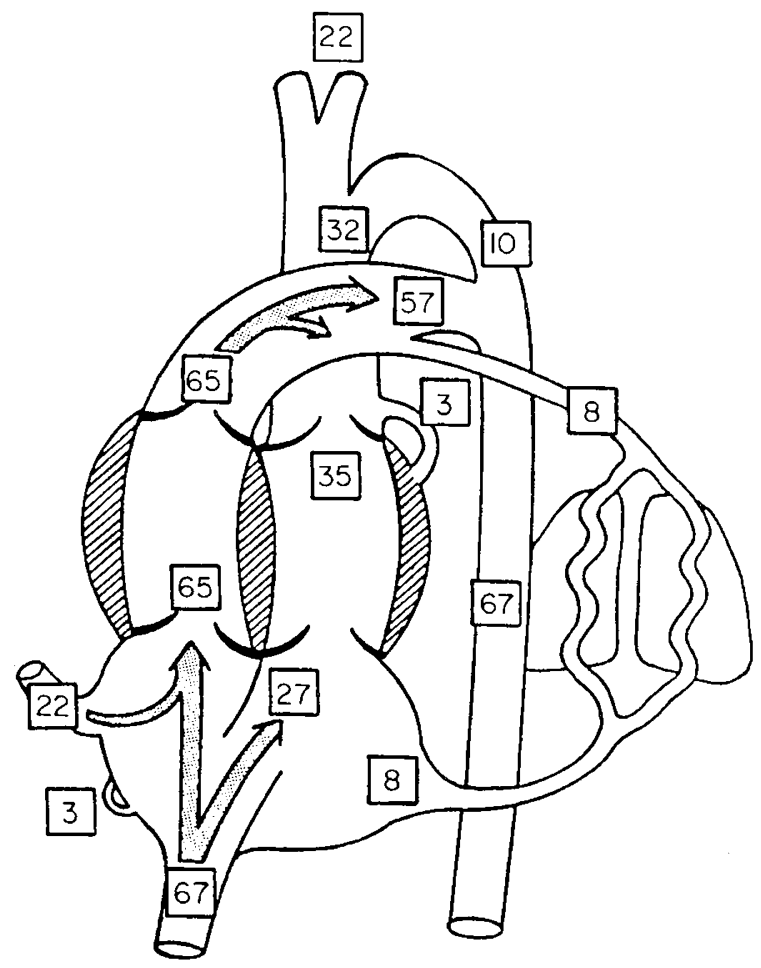

Fig. 2. Blood flows during the control period. Numbers in boxes represent the percentage of CVO in the cardiac chambers, central blood vessels, and through the central shunts. Refer to Figure 1 for chamber and vessel identification.
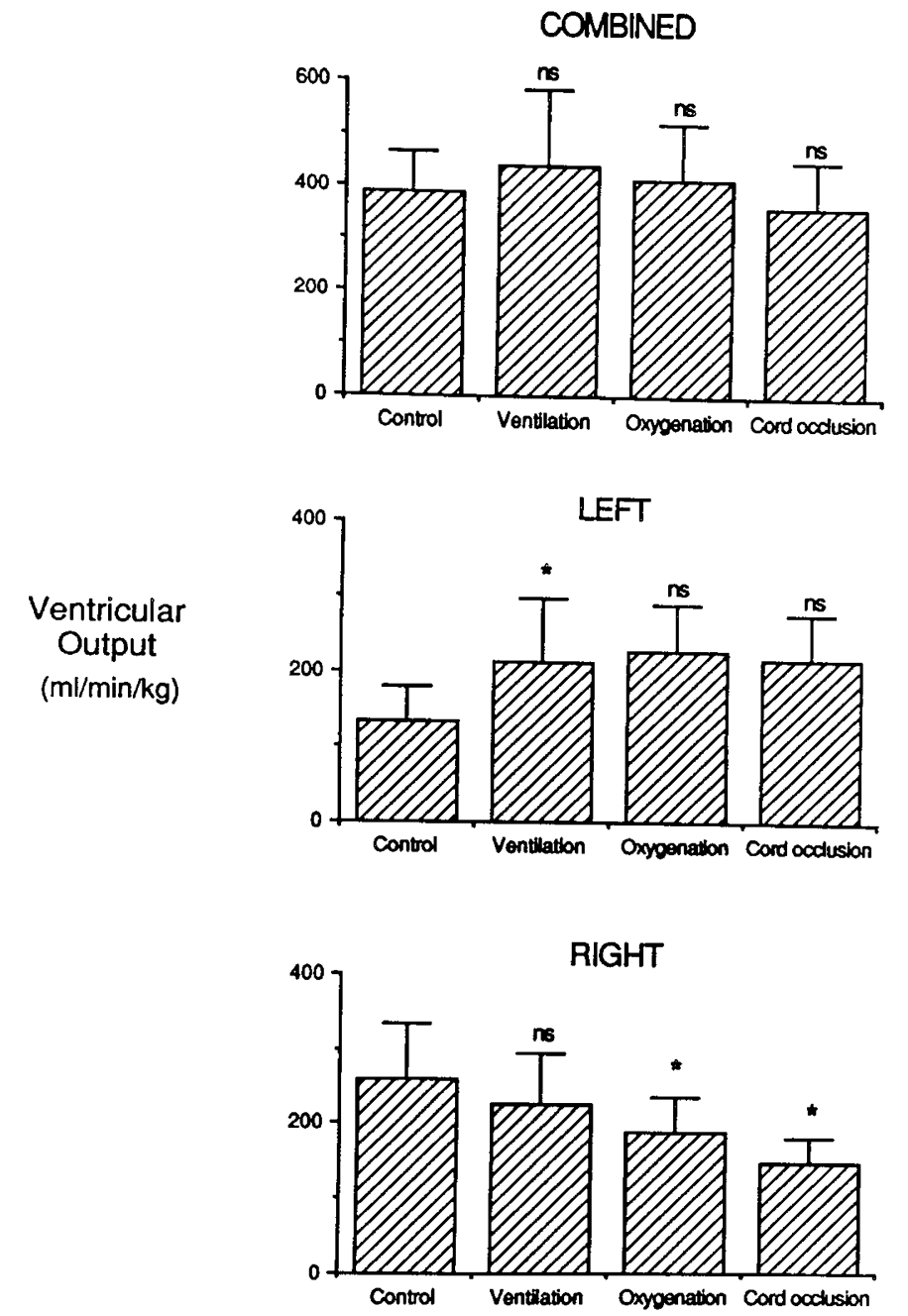

Fig. 3. Ventricular outputs during the control period, ventilation, oxygenation, and after umbilical cord occlusion. The boxes represent mean values and the bars represent $1 \mathrm{SD}$ above the mean. ${ }^{*}$ Significantly different from the condition immediately preceding it, $p \leq 0.01$. $n s$, not significantly different from the condition immediately preceding it.

the lower body $(83 \pm 28 \mathrm{ml} / \mathrm{min} / \mathrm{kg})$ decreased but placental blood flow did not change $(134 \pm 73 \mathrm{ml} / \mathrm{min} / \mathrm{kg})$. A variable but very small left to right shunt through the ductus arteriosus was calculated $(17 \pm 30 \mathrm{ml} / \mathrm{min} / \mathrm{kg})$. Inferior vena caval return to the right atrium decreased, and blood flow through the foramen ovale decreased to a similar degree (to $66 \pm 40 \mathrm{ml} / \mathrm{min} / \mathrm{kg}$ ). Although left ventricular output increased to $211 \pm 87 \mathrm{ml} / \mathrm{min} /$ $\mathrm{kg}, \mathrm{CVO}$ did not change significantly (Fig. 3).

Oxygenation. Continued ventilation, but with substitution of the fetal gas mixture with $100 \%$ oxygen, caused a large increase in arterial blood oxygen tension but did not change $\mathrm{pH}$ or $\mathrm{pCO}_{2}$ (Table 1). There were further significant changes in central blood flow patterns (Fig. 6). The right ventricle ejected significantly less blood $(187 \pm 47 \mathrm{ml} / \mathrm{min} / \mathrm{kg})$, and only a negligible fraction of its output $(14 \pm 14 \mathrm{ml} / \mathrm{min} / \mathrm{kg})$ passed through the ductus arteriosus to the descending aorta. The left ventricle ejected 227 $\pm 64 \mathrm{ml} / \mathrm{min} / \mathrm{kg}$, more than one-half of CVO, but less perfused the heart, brain, and upper body $(50 \pm 13 \mathrm{ml} / \mathrm{min} / \mathrm{kg})$ and more crossed the aortic isthmus to the descending aorta $(179 \pm 59 \mathrm{ml} /$ $\mathrm{min} / \mathrm{kg}$ ). Despite the large increase in isthmic blood flow, a lesser proportion of blood actually perfused the lower body $(61 \pm 27$ $\mathrm{ml} / \mathrm{min} / \mathrm{kg})$ and placenta $(89 \pm 45 \mathrm{ml} / \mathrm{min} / \mathrm{kg})$ and a significant left to right shunt through the ductus arteriosus developed (41 \pm $26 \mathrm{ml} / \mathrm{min} / \mathrm{kg}$ ). The dominant direction of blood flow through the ductus arteriosus therefore was reversed, becoming left to 


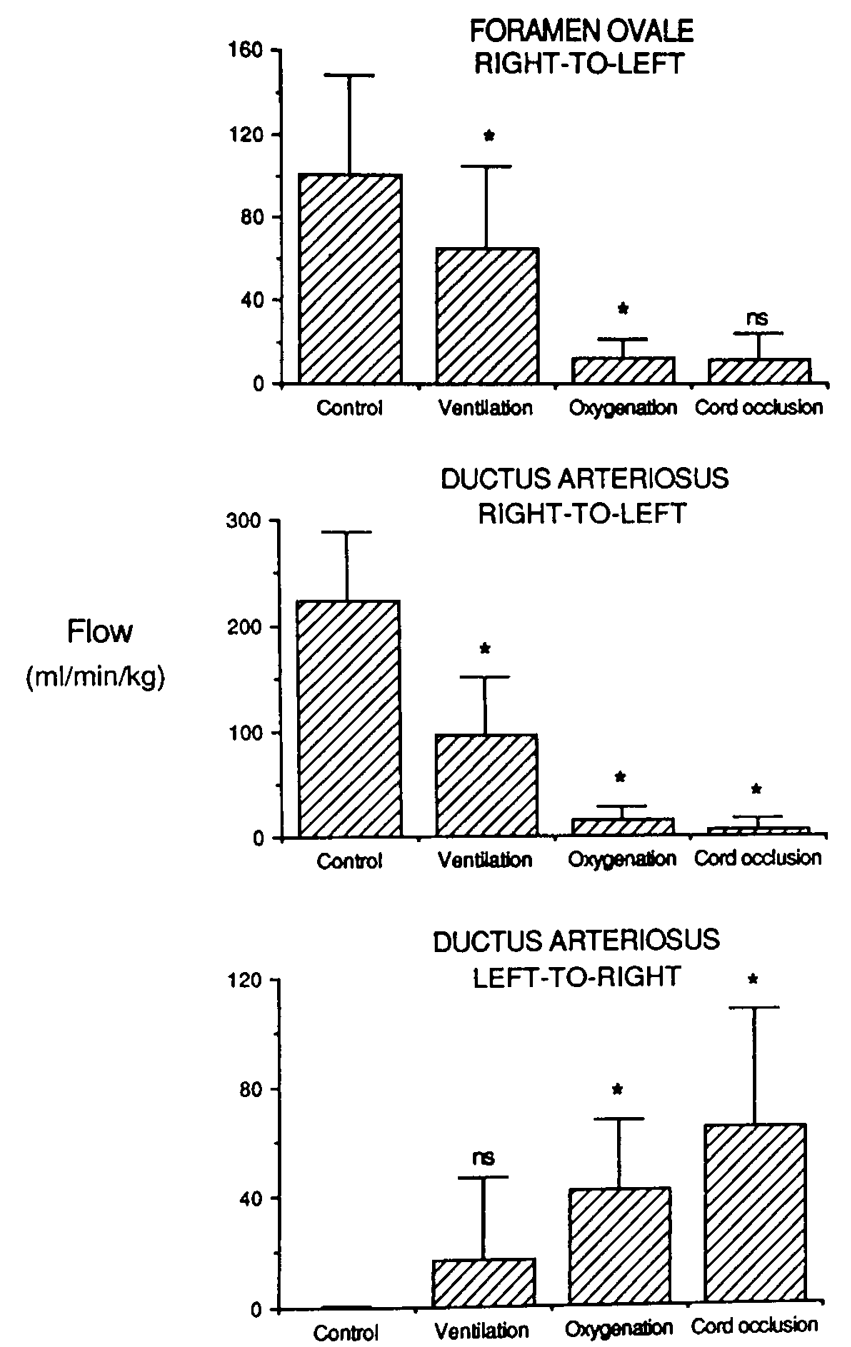

Fig. 4. Blood flow through central shunts during the control period, ventilation, and oxygenation, and after umbilical cord occlusion. The boxes represent mean values and the bars represent $1 \mathrm{SD}$ above the mean. *Significantly different from the condition immediately preceding it, $p \leq 0.01$. $n s$, not significantly different from the condition immediately preceding it.

right. The right to left shunt through the foramen ovale again decreased significantly and to near negligible levels $(13 \pm 10 \mathrm{ml} /$ $\min / \mathrm{kg}$ ).

Umbilical Cord Occlusion. Occlusion of the umbilical cord during continued ventilation with $100 \%$ oxygen caused little further changes in central blood flow patterns (Fig. 7). The right ventricle ejected somewhat less blood $(144 \pm 36 \mathrm{ml} / \mathrm{min} / \mathrm{kg})$ but the output of the left ventricle did not change $(215 \pm 63 \mathrm{ml} /$ $\mathrm{min} / \mathrm{kg}$ ). The right to left shunts through the ductus arteriosus $(6 \pm 10 \mathrm{ml} / \mathrm{min} / \mathrm{kg})$ and foramen ovale $(12 \pm 13 \mathrm{ml} / \mathrm{min} / \mathrm{kg})$ remained negligible and the left to right shunt through the ductus arteriosus increased significantly $(65 \pm 43 \mathrm{ml} / \mathrm{min} / \mathrm{kg})$. Placental blood flow was essentially abolished $(11 \pm 19 \mathrm{ml} / \mathrm{min} / \mathrm{kg})$ and flows to the upper body, heart, and brain $(57 \pm 13 \mathrm{ml} / \mathrm{min} / \mathrm{kg})$ and lower body $(88 \pm 26 \mathrm{ml} / \mathrm{min} / \mathrm{kg})$ did not change significantly.

Hemodynamics. Changes in heart rate and mean vascular pressures are presented in Table 3. Control values were similar to those previously reported in the normoxemic, chronically instrumented sheep fetus (16-19). After a modest decrease in heart rate during ventilation (from $173 \pm 25$ to $152 \pm 16 \mathrm{bpm}$ ), no further changes were seen. Mean descending aortic pressure did not change with ventilation but did decrease modestly with oxygenation (from $53 \pm 6$ to $48 \pm 6 \mathrm{~mm} \mathrm{Hg}$ ). Umbilical cord

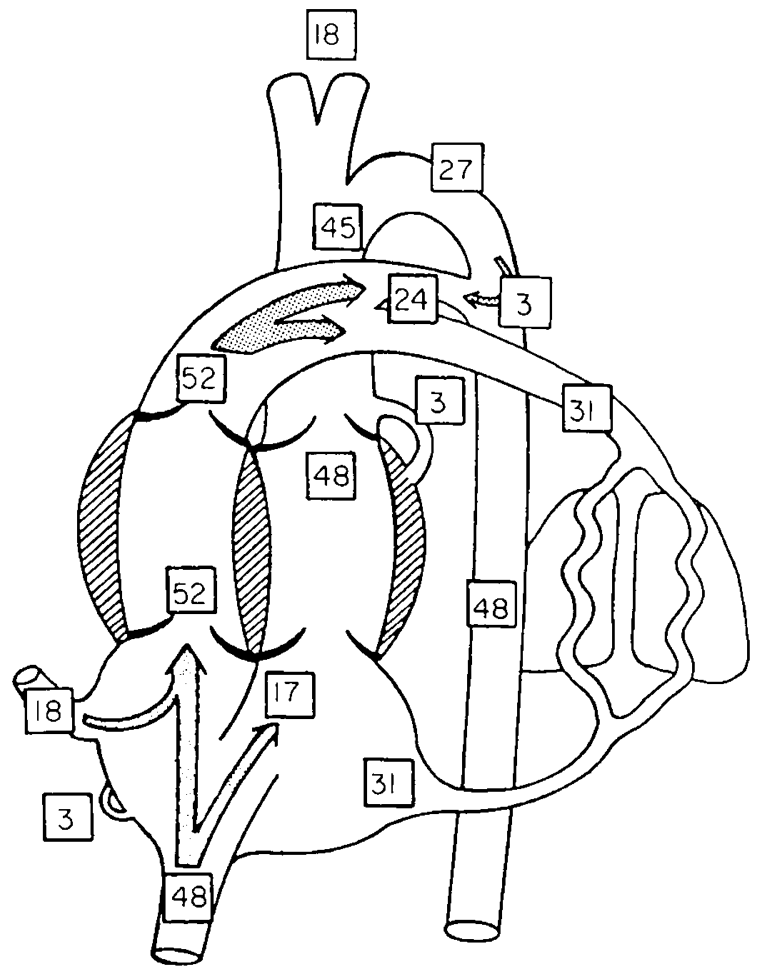

Fig. 5. Blood flows during ventilation with no change in fetal arterial blood gases. Numbers in boxes represent the percentage of CVO in the cardiac chambers, central blood vessels, and through the central shunts. Refer to Figure 1 for chamber and vessel identification.

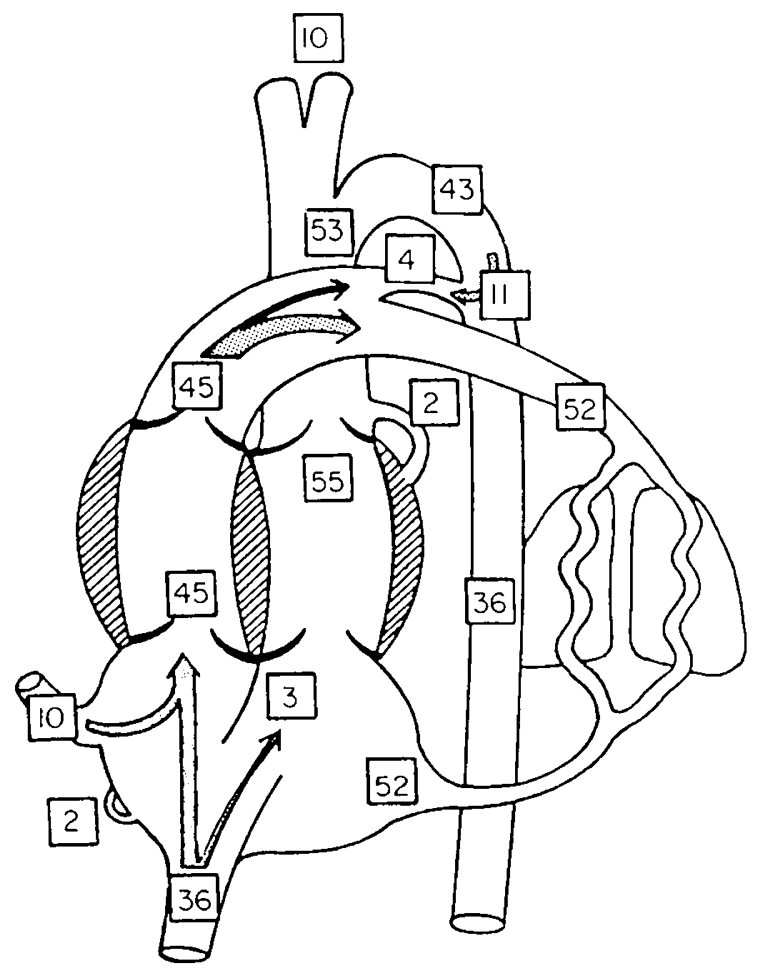

Fig. 6. Blood flows during ventilation with $100 \%$ oxygen. Numbers in boxes represent the percentage of CVO in the cardiac chambers, central blood vessels, and through the central shunts. Refer to Figure 1 for chamber and vessel identification.

occlusion caused a variable but not significant change in pressure $(58 \pm 16 \mathrm{~mm} \mathrm{Hg})$. Mean pulmonary arterial pressure changed in accordance with descending aortic pressure and was never significantly different. This is markedly dissimilar to the changes 
seen in filling pressures. Although central venous pressure did not change throughout the study, left atrial pressure more than doubled with ventilation (from $3 \pm 3$ to $7 \pm 4 \mathrm{~mm} \mathrm{Hg}$ ) and remained high during oxygenation $(8 \pm 4 \mathrm{~mm} \mathrm{Hg})$ and umbilical cord occlusion $(10 \pm 4 \mathrm{~mm} \mathrm{Hg})$. Mean left atrial pressure was significantly higher than central venous pressure during oxygenation and umbilical cord occlusion. This large separation in filling pressure and the anatomy of the foramen ovale excludes a significant left to right shunt through the foramen ovale during oxygenation and umbilical cord occlusion (2).

\section{DISCUSSION}

Three major components of the birth process are rhythmic gaseous distension, or ventilation, of the lung, an increase in arterial oxygenation, and a loss of the umbilical-placental circulation by occlusion of the umbilical cord. We found that these three components are responsible for most of the changes in central blood flow patterns that occur at birth: the circulation changed from one characterized by low pulmonary blood flow, a dominant right ventricle, and right to left shunts through the

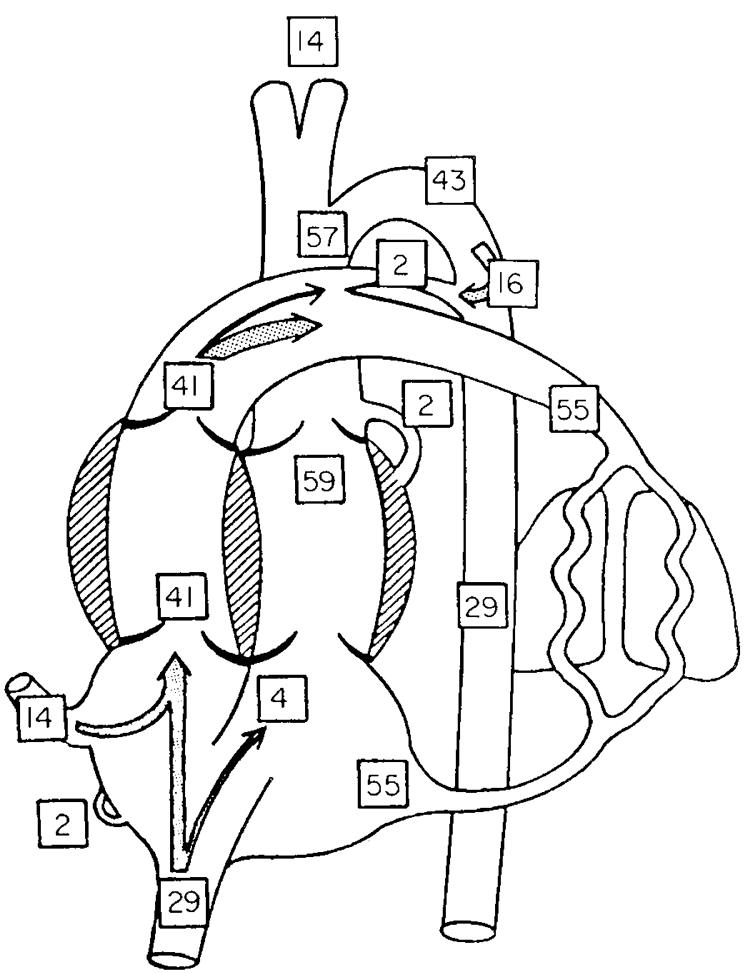

Fig. 7. Blood flows after umbilical cord oclussion. Numbers in boxes represent the percentage of $\mathrm{CVO}$ in the cardiac chambers, central blood vessels, and through the central shunts. Refer to Figure 1 for chamber and vessel identification. ductus arteriosus and foramen ovale, to one characterized by high pulmonary blood flow, a dominant left ventricle, and a transient left to right shunt through the ductus arteriosus. Despite an increase in left ventricular output, the increase in combined ventricular output normally seen at birth did not occur.

We found that ventilation of the fetal lung alone, without increasing arterial oxygen content, caused much of the redistribution of central blood flow. Rhythmic physical expansion of the lungs was associated with an increase in left ventricular output from one-third to nearly one-half of combined ventricular output, a 4-fold increase in pulmonary blood flow, and large decreases in the right to left shunts through both the ductus arteriosus and the foramen ovale. All these effects of ventilation could be attributed to a large decrease in pulmonary vascular resistance, as reflected by a large increase in pulmonary blood flow. Oxygenation and umbilical cord occlusion were associated with a further increase in pulmonary blood flow, abolition of the right to left shunts through the ductus arteriosus and foramen ovale, and the appearance of a left to right shunt through the ductus arteriosus. These effects could be attributed to a further decrease in pulmonary vascular resistance and increases in systemic and umbilical vascular resistances, as reflected by the increase in pulmonary blood flow, decrease in fetal body blood flow, and abolition of the umbilical-placental circulation.

Our preparation, which simulates these three components of the birth process in utero, has many advantages over previous studies. We were able to determine the sequential effects of ventilation, oxygenation, and umbilical cord occlusion without the effects of normal labor, delivery, and exposure to cold. The normal stress of labor and delivery markedly increase circulating catecholamines (20), and cutaneous cold stimulation alters cardiovascular and electrocortical activity (21). Moreover, we studied chronically instrumented sheep fetuses after a recovery period, and thus reduced the influence of surgery and excluded the effects of anesthesia and acute exteriorization (10). Using an acute open-chest preparation, Assali et al. (9) demonstrated that ventilation without oxygenation caused an increase in left atrial over right atrial pressure, indirectly suggesting that foramen ovale flow decreased or ceased, that a left to right shunt through the ductus arteriosus probably developed in some lambs, and that left ventricular output increased. However, cardiac output was extremely low in those animals, and thus central blood flow patterns may also have been abnormal. Also using an acute, open-chest preparation, Dawes et al. (2) suggested that a left to right shunt through the ductus arteriosus may have already developed during ventilation alone, because subsequent occlusion of the ductus arteriosus caused a decrease in left atrial pressure. They were not able to measure absolute ventricular outputs or central blood flow patterns. Willis et al. (22) have previously demonstrated the feasibility of ventilating the sheep fetus in utero and Morton et al. (11) subsequently studied the effects of ventilation with oxygen on left ventricular output.

There are two disadvantages of our preparation: we can determine only the sequential effects of ventilation, oxygenation, and cord occlusion but not their independent effects, and ventilation

Table 3. Heart rate and mean vascular pressures (mean $\pm 1 S D)^{*}$

\begin{tabular}{lcccc}
\hline & Control & Ventilation & Oxygenation & Cord occlusion \\
\hline $\begin{array}{l}\text { Heart rate }(\mathrm{bpm}) \\
\text { Mean vascular pressures }\end{array} \quad 173 \pm 25(16)$ & $152 \pm 16 \dagger(16)$ & $152 \pm 21(16)$ & $163 \pm 46(12)$ \\
$\quad(\mathrm{mm} H \mathrm{Hg})$ : & & & & \\
$\quad$ Descending aortic & $52 \pm 6(16)$ & $53 \pm 6(16)$ & $48 \pm 6 \dagger(16)$ & $58 \pm 16(12)$ \\
Pulmonary arterial & $53 \pm 8(16)$ & $55 \pm 9(16)$ & $47 \pm 6 \dagger(16)$ & $48 \pm 16(12)$ \\
Central venous & $3 \pm 3(12)$ & $4 \pm 3(9)$ & $3 \pm 4(10)$ & $3 \pm 3(8)$ \\
$\quad$ Left atrial & $3 \pm 3(12)$ & $7 \pm 4 \dagger(11)$ & $8 \pm 4 \ddagger(11)$ & $10 \pm 4 \ddagger(8)$ \\
\hline
\end{tabular}

* Values of $\mathrm{n}$ for each variable are given because the central venous and left atrial catheters did not always function throughout the study.

+ Significantly different from the condition immediately preceding it, $p \leq 0.05$.

$\ddagger$ Left atrial pressure significantly greater than central venous pressure during the same condition, $p \leq 0.05$. 
is by positive rather than negative pressure. The effects of oxygenation independent of ventilation were addressed by Assali $e t$ al. (23) when they exposed acutely exteriorized sheep fetuses to hyperbaric oxygen. They showed that left ventricular output increased by $50 \%$ and the ductus right to left shunt decreased to one-third of control. They estimated that pulmonary blood flow increased almost threefold and that foramen ovale flow decreased $50 \%$, although these calculations were based on mean values of ventricular outputs and flows through the ductus arteriosus that were measured in different fetuses. These changes were not as pronounced as those we found with ventilation and oxygenation. However, this study was also notable for the very low values of ventricular output, probably caused by the preparation itself. Thus, the limited responses in ventricular output, pulmonary blood flow, and central shunt patterns may either indicate that the effects of ventilation and oxygenation are cumulative or that the acute surgical procedure and exteriorization of the fetus limited its response to oxygen. Our use of positive pressure ventilation may affect central blood flow patterns by limiting systemic venous return to the right ventricle and increasing pulmonary vascular resistance, both of which may decrease pulmonary blood flow. However, an in utero preparation necessitates the use of positive pressure and the pulmonary effects of gaseous distension and oxygenation still occur and appear dramatic. In addition, we performed studies after $48-72 \mathrm{~h}$ recovery, which may limit the cardiovascular response to some extent.

It is possible to ascribe all the changes in central blood flow patterns that we saw to changes in the relative vascular resistances of the pulmonary, systemic, and umbilical circulations. Ventilation without oxygenation has been shown to decrease pulmonary vascular resistance modestly $(16 \%)$ in the isolated perfused lungs of fetal sheep (24), whereas we found that it caused a 4-fold increase in pulmonary blood flow, indicating a far greater decrease in resistance. Ventilation alone did not cause significant changes in fetal body or placental blood flow or vascular pressures. The isolated decrease in pulmonary vascular resistance would direct right ventricular output more toward the lungs and less down the ductus arteriosus. The increase in pulmonary blood flow would increase pulmonary venous blood returning to the left atrium, which in turn would decrease the right to left shunt through the foramen ovale. The volume of pulmonary venous blood returning to the left atrium also exceeded the volume normally shunted right to left across the foramen ovale, and thus left ventricular output would increase.

Oxygenation of the fetus further increased pulmonary blood flow and also decreased flow to the upper body and placenta. At the same time pulmonary and systemic arterial mean pressures decreased somewhat. Thus, pulmonary vascular resistance fell markedly and systemic vascular resistance did not change. A major effect of this change in relative resistances was the change in the dominant direction of blood flow through the ductus arteriosus, from right to left to left to right. The increase in pulmonary venous blood returning to the left atrium would further decrease the right to left shunt through the foramen ovale. Occlusion of the umbilical cord removed the umbilical-placental circulation, increasing combined systemic-umbilical resistance. This would direct more of the left ventricular output across the ductus arteriosus into the lungs, thereby increasing pulmonary blood flow and essentially abolishing the right to left shunt through the foramen ovale. Thus, all the changes in the central blood flow patterns can be attributed to changes in pulmonary and systemic-umbilical vascular resistances.

Left ventricular output increased significantly in our study, far more than occurs in response to volume loading in the sheep fetus $(17,25)$ but less than that which occurs at birth $(6)$ or occurred in the study of Morton et al. (11). The lesser response compared to the latter two studies can best be explained by the different heart rate responses. At birth, Lister et al. (6) found that heart rate was well above fetal levels and similar to that found by Morton et al. (11) in response to in utero oxygenation (heart rate increased from $160 \pm 21$ to $183 \pm 11 \mathrm{bpm}$ ). This contrasts to our study, in which heart rate fell $12 \%$. The increase in heart rate found at birth may be caused by the catecholamine surge that normally occurs $(26,27)$, but, in the study of Morton et al. (11), the increase was probably related to the parasympathetic blocking effects of atropine because sympathetic stimulation was also blocked by propranolol. It is unlikely, however, that the lesser increase in left ventricular output in our study was caused by a limited inotropic response related to a shorter recovery period, because we actually found a somewhat greater percentage increase in stroke volume than did Morton et al. (11) when comparing oxygenation values to control (93 versus $73 \%$ ).

Another difference in our findings compared to those of Morton et al. (11) was the response to ventilation without oxygenation: whereas they found no significant increase in left ventricular output, the majority of the increase in our study occurred during ventilation prior to oxygenation. However, Morton et al. (11) studied only four fetuses, three of which were studied after oxygenation, and there was a large variability in the values for output $(209 \pm 167 \mathrm{ml} / \mathrm{min} / \mathrm{kg})$, making any statistical analysis problematic. It is therefore difficult to make meaningful comparisons with our findings.

Left ventricular output increased to a far greater extent in our study than that previously described in response to volume loading $(17,25)$. This may be caused by a variety of mechanisms, but two possibilities stand out. During volume loading, the preload of each ventricle increases similarly (25). In our study, however, the filling pressure of the left ventricle (left atrial pressure) more than doubled while that of the right (central venous pressure) did not change. The lower right ventricular filling pressure may increase the diastolic compliance of the left ventricle by exerting less direct compressive effects, and thus left ventricular end-diastolic volume may be able to increase to a greater extent than during volume loading alone: this in turn would allow left ventricular output to increase to a greater extent as well. Alternatively, differences in the afterload of the left ventricle in the two situations may explain the differences in output. The absence of a significant decrease in afterload during volume loading may limit the ability of the left ventricle to increase its output. Ross (28) has described this phenomenon in patients with congestive heart failure, who will increase cardiac output in response to volume loading only when there is a simultaneous reduction in afterload, and has called it "afterload mismatch and preload reserve." In our study, however, the afterload of the left ventricle probably decreased greatly: the left ventricle was exposed to the pulmonary vascular bed because the ductus arteriosus was patent, and there was a large decrease in pulmonary vascular resistance without a significant change in systemic vascular resistance. This decrease in afterload may have potentiated the increase in left ventricular output in response to the increase in preload.

Although left ventricular output increased more than it does in response to volume loading, right ventricular output decreased and combined ventricular output did not change significantly. The decrease in right ventricular output may be related to the absence of increase in heart rate and right ventricular filling pressure. As described above, right ventricular filling pressure did not increase despite a large increase in left ventricular filling pressure. The development of a filling pressure gradient from left to right may shift septal alignment into the right ventricle (diastolic ventricular interdependence), thus limiting right ventricular filling. Thus a similar right ventricular filling pressure may actually be associated with a lesser right ventricular end-diastolic volume and a lesser output of blood. Systolic interdependence may also play a role, because, as left ventricular output increased and its afterload decreased, its ejection volume increased significantly, potentially altering its dynamic geometry of contraction and directly impairing the right ventricular pattern of contraction.

The absence of an increase in combined ventricular output 
occurred in association with a modest decrease in heart rate. These findings may best be explained by a lesser demand for oxygen than that which normally occurs at birth (6), but a lesser ability of the heart to increase its output in response to a similar demand cannot be excluded. Oxygen demand was almost certainly much less in our preparation than after birth. Increased oxygen requirements at birth result from the need of the newborn animal to maintain its own body temperature and also from the energy expenditure for breathing. Increased oxygen consumption related to the metabolic activities concerned with maintenance of body temperature is at least in part the result of catecholamine effects. It is known that plasma catecholamine concentrations increase after birth $(26,27)$ and Padbury et al. (29) have suggested that the event which stimulates catecholamine release is occlusion of the umbilical cord. We do not know whether plasma catecholamine concentrations increased in our preparation, but combined ventricular output did not change when the umbilical cord was occluded. Another important difference between normal birth and our study is the presence of prenatal increases in plasma cortisol and thyroid hormone concentrations that occur just prior to normal delivery $(30,31)$. Breall et al. (32) have shown that fetal sheep subjected to thyroidectomy about 2 wk prior to delivery do not demonstrate the increases in cardiac output and heart rate which occur in normal lambs after delivery (5). The reasons for these differences are not apparent, but it has been suggested that the lack of thyroid hormone may interfere with $\beta$-adrenoreceptor number or maturational development (33, 34 ) or that it may influence $\mathrm{Na}^{+}, \mathrm{K}^{+}$-ATPase activity (35). Even with the same demand for oxygen, therefore, the hearts of fetuses not exposed to these hormonal surges may not be capable of increasing their outputs appropriately. The preparation we have described will provide the opportunity to assess the effects of prenatal hormonal influences on postnatal circulatory adaptation.

In summary, we have used an in utero preparation to determine the sequential effects of ventilation, oxygenation, and umbilical cord occlusion on central blood flow patterns in late gestation fetal sheep. The majority of the transition from the fetal to neonatal circulation is initiated by ventilation alone, and can be explained by a decrease in pulmonary vascular resistance. The further decrease in pulmonary vascular resistance and increase in systemic-umbilical vascular resistances caused by oxygenation and umbilical cord occlusion create the complete neonatal circulatory pattern. However, none of these components of the birth process is alone responsible for the large increase in combined ventricular output seen at birth.

\section{REFERENCES}

1. Heymann MA, Creasy RK, Rudolph AM 1973 Quantitation of blood flow pattern in the foetal lamb in utero. In: Proceedings of the Sir Joseph Barcroft Centenary Symposium: Foetal and Neonatal Physiology. Cambridge University Press, Cambridge, pp 129-135

2. Dawes GS, Mott JC, Widdicombe JG 1955 Closure of the foramen ovale in newborn lambs. J Physiol 128:384-395

3. Moss AJ, Emmanouilides G, Duffie ER 1963 Closure of the ductus arteriosus in the newborn infant. Pediatrics 32:25-30

4. Rudolph AM, Drorbaugh JE, Auld PAM, Rudolph AJ, Nadas AS, Smith CA, Hubbell JP 1961 Studies on the circulation in the neonatal period: the circulation in the respiratory distress syndrome. Pediatrics 27:551-566

5. Klopfenstein HS, Rudolph AM 1978 Postnatal changes in the circulation, and the responses to volume loading in sheep. Circ Res 42:839-845.

6. Lister G, Walter TK, Versmold HT, Dallman PR, Rudolph AM 1979 Oxygen delivery in lambs: cardiovascular and hematologic development. Am J Physiol 237:H668-H675

7. Assali NS, Sehgal N, Marable S 1962 Pulmonary and ductus arteriosus circulation in the fetal lamb before and after birth. Am J Physiol 202:536-540

8. Cassin S, Dawes GS, Mott JC, Ross BB, Strang LB 1963 The vascular resistance of the foetal and newly ventilated lung of the lamb. J Physiol 171:61-79

9. Assali NS, Morris JA, Beck R 1965 Cardiovascular hemodynamics in the fetal lamb before and after lung expansion. Am J Physiol 208:122-129

10. Heymann MA, Rudolph AM 1967 Effect of exteriorization of the sheep fetus on its cardiovascular function. Circ Res 21:741-745

11. Morton MJ, Pinson CW, Thornburg KL 1987 In utero ventilation with oxygen augments left ventricular stroke volume in lambs. J Physiol 383:413-424

12. Iwamoto HS, Rudolph AM 1983 Chronic renal venous catheterization in fetal sheep. Am J Physiol 245:H524-H527

13. Solca M, Kolobow T, Huang H, Pesenti A, Buckhold D, Pierce JE 1983 Management of the antenatal preterm fetal lung in the prevention of respiratory distress syndrome in lambs. Biol Neonate 44:93-110

14. Boychuk RB, Rigatto $H$, Seshia MMK 1977 The effect of lung inflation on the control of respiratory frequency in the neonate. J Physiol (Lond) 270:653659

15. Baer RW, Payne BD, Verrier ED, Vlahakes GJ, Molodowitch D, Uhlig PN, Hoffman JIE 1984 Increased number of myocardial blood flow measurements with radionuclide-labeled microspheres. Am J Physiol 246:H418$\mathrm{H} 434$

16. Anderson DF, Bissonnette JM, Faber JJ, Thornburg KL 1981 Central shunt flows and pressures in the mature fetal lamb. Am J Physiol 241:H60-H66

17. Thornburg KL, Morton MJ 1983 Filling and arterial pressures as determinants of RV stroke volume in the sheep fetus. Am J Physiol 244:H656-H663

18. Toubas PL, Silverman NH, Heymann MA, Rudolph AM 1981 Cardiovascular effects of acute hemorrhage in fetal lambs. Am J Physiol 240:H45-H48

19. Iwamoto HS, Rudolph AM, Mirkin BL, Keil LC 1983 Circulatory and humoral responses of sympathectomized fetal sheep to hypoxemia. Am J Physiol 245:H767-H772

20. Jones CM III, Greiss FC 1982 The effect of labor on maternal and fetal circulating catecholamines. Am J Obstet Gynecol 144:149-153

21. Gluckman PD, Gunn TR, Johnston BM 1983 The effect of cooling on breathing and shivering in unanesthetized fetal lambs in utero. $\mathbf{J}$ Physiol 343:495-506

22. Willis DM, Anderson DF, Thornburg KL, Faber JJ 1985 Alteration of arterial gas composition by positive pressure ventilation in the unanesthetized fetal lamb in utero. Biol Neonate 47:295-304

23. Assali NS, Kirschbaum TH, Dilts W Jr 1968 Effects of hyperbaric oxygen on uteroplacental and fetal circulation. Circ Res 22:573-588

24. Leffler CW, Hessler JR, Green RS 1984 Mechanism of stimulation of pulmonary prostacyclin synthesis at birth. Prostaglandins 28:877-887

25. Gilbert RD 1980 Control of fetal cardiac output during changes in blood volume. Am J Physiol 238:H80-H86

26. Lagercrantz H, Bistoletti P 1973 Catecholamine release in the newborn infants at birth. Pediatr Res 14:278-281

27. Padbury JF, Roberman B, Oddie TH, Hobel CJ,.. Fisher DA 1982 Fetal catecholamine release in response to labor and delivery. Obstet Gynecol 60:607-611

28. Ross J Jr 1976 Afterload mismatch and preload reserve: a conceptual framework for the analysis of ventricular function. Prog Cardiovasc Dis 28:255264

29. Padbury JF, Diakomanolis ES, Hobel CJ, Perelman A, Fisher DA 1981 Neonatal adaptation: sympatho-adrenal response to umbilical cord cutting.
Pediatr Res 15:1483-1487

30. Alexander DP, Britton HG, Nixon DA, Ratcliffe JG, Redstone D 1973 Corticotropin and cortisol concentrations in the plasma of the chronically catheterized sheep fetus. Biol Neonate 23:184-192

31. Sack J, Beaudry M, DeLamater PV, Oh W, Fisher DA 1976 Umbilical cord cutting triggers hypertriiodothyroninemia and nonshivering thermogenesis in the newborn lamb. Pediatr Res 10:169-175

32. Breall JA, Rudolph AM, Heymann MA 1984 Role of thyroid hormone in postnatal circulatory and metabolic adjustments. J Clin Invest 73:14181424

33. Whitsett JA, Noguchi A, Moore JJ 1982 Developmental aspects of alpha- and beta-adrenergic receptors. Semin Perinatol 6:125-141

34. Williams LT, Lefkowitz RJ, Watanabe SM, Hathaway DR Besch HR 1977 Thyroid hormone regulation of beta-adrenergic receptor number. J Biol Chem 252:2787-2789

35. Philipson KD, Edelman IS 1977 Thyroid hormone control of $\mathrm{Na}^{+}$and $\mathrm{K}^{+}$ATPase and $\mathrm{K}^{+}$-dependent phosphatase in rat heart. Am J Physiol 232:C196C206

\section{APPENDIX 1}

Calculations using an inferior vena caval injection and triple withdrawals in the absence of a left-to-right shunt through the ductus arteriosus:

\section{Upper body blood flow}

$$
\mathrm{Q}_{\mathrm{UB}}=\mathrm{S}_{\mathrm{UB}} \times \mathrm{Q}_{\mathrm{ref}} / \mathrm{S}_{\mathrm{ref}},
$$

where $\mathrm{Q}_{\mathrm{UB}}$ is upper body blood flow, $\mathrm{S}_{\mathrm{UB}}$ is the total number of counts of that isotope recovered in the upper body, $Q_{\text {ref }}$ is the reference flow rate in the ascending aorta, $S_{\text {ref }}$ is the counts recovered in the ascending aortic reference sample.

\section{Lower body (and placental) blood flow}

$$
\mathrm{Q}_{\mathrm{LB}}=\mathrm{S}_{\mathrm{LB}} \times \mathrm{Q}_{\mathrm{ref}} / \mathrm{S}_{\mathrm{ref}},
$$

where $Q_{L B}$ is lower body and placental blood flow, $S_{L B}$ is the total number of counts of that isotope recovered in the lower body and placenta, $\mathrm{Q}_{\mathrm{ref}}$ is the reference flow rate in the descending aorta, $S_{\text {ref }}$ is the counts recovered in the descending aortic reference sample. 


\section{Pulmonary blood flow}

$$
\mathrm{Q}_{\mathrm{I.Gi}}=\mathrm{S}_{\mathrm{LC} ;} \times \mathrm{Q}_{\mathrm{ref}} / \mathrm{S}_{\mathrm{ref}}
$$

where $Q_{L, G}$ is pulmonary blood flow, $S_{L, G}$ is the total number of counts of that isotope recovered in the lungs, $Q_{\text {ret }}$ is the reference flow rate in the pulmonary artery, $S_{\text {ref }}$ is the counts recovered in the pulmonary arterial reference sample.

4. Right-to-left shunt through the ductus arteriosus ( $\left.Q_{\mathrm{DRL}}\right)$. The total number of IVC microspheres recovered in the lower body and placenta may be calculated either as the product of the concentration of microspheres in the descending aortic reference sample and the blood flow to the lower body and placenta, or by the sum of the contributions of IVC microspheres from the left ventricle (via the aortic isthmus) and from the right ventricle (via the ductus arteriosus). Thus,

$$
S_{\mathrm{L} . \mathrm{B}}^{\mathrm{L}}=C_{\mathrm{FA}} \times Q_{\mathrm{LB}}=\left(C_{\mathrm{PA}} \times Q_{\mathrm{DRI}}\right)+\left(\mathrm{C}_{\mathrm{CA}} \times \mathrm{Q}_{\mathrm{IS}}\right)
$$

where $S_{L_{B}}$ is the number of IVC microspheres recovered from the lower body and placenta, $C_{F A}$ is the concentration of microspheres in the descending aortic (femoral arterial) reference sample, $C_{\mathrm{PA}}$ is the concentration of microspheres in the pulmonary arterial reference sample, $C_{C \wedge}$ is the concentration of microspheres in the ascending aortic (carotid arterial) reference sample, and $Q_{I S}$ is the blood flow through the aortic isthmus.

Lower body blood flow $\left(\mathrm{Q}_{\mathrm{LB}}\right)$ is equal to flow through the ductus arteriosus and aortic isthmus:

or

$$
\mathrm{Q}_{\mathrm{LB}}=\mathrm{Q}_{\mathrm{DRL}}+\mathrm{Q}_{\mathrm{IS}}
$$

$$
\mathrm{Q}_{\mathrm{IS}}=\mathrm{Q}_{\mathrm{LB}}-\mathrm{Q}_{\mathrm{DRI}}
$$

Substituting equation 2 for $\mathrm{Q}_{\mathrm{IS}}$ in equation 1, then

$$
\mathrm{C}_{\mathrm{FA}} \times \mathrm{Q}_{1 . \mathrm{B}}=\mathrm{C}_{\mathrm{PA}} \times \mathrm{Q}_{\mathrm{DRL} .}+\mathrm{C}_{\mathrm{CA}} \times \mathrm{Q}_{\mathrm{LB}}-\mathrm{C}_{\mathrm{CA}} \times \mathrm{Q}_{\mathrm{DRL}}
$$

rearranging,

$$
\mathrm{Q}_{\mathrm{DRI}}=\mathrm{Q}_{\mathrm{LB}} /\left\{1+\left(\mathrm{C}_{\mathrm{PA}}-\mathrm{C}_{\mathrm{FA}}\right) /\left(\mathrm{C}_{\mathrm{FA}}-\mathrm{C}_{\mathrm{CA}}\right)\right\}
$$

5. Right-to-left shunt through the foramen ovale $\left(Q_{\mathrm{FO}}\right)$. The right-to-left shunt through the foramen ovale is equal to the systemic venous return $\left(\mathrm{Q}_{\mathrm{LB}}+\mathrm{Q}_{\mathrm{UB}}\right)$ less the right ventricular output $\left(\mathrm{Q}_{\mathrm{I} . \mathrm{i}}+\mathrm{Q}_{\mathrm{DRI}}\right)$

$$
\mathrm{Q}_{\mathrm{FO}}=\mathrm{Q}_{\mathrm{LBB}}+\mathrm{Q}_{\mathrm{UB}}-\mathrm{Q}_{\mathrm{LC} ;}-\mathrm{Q}_{\mathrm{DRL}}
$$

6. Left ventricular output ( $L V O)$

$$
\mathrm{LVO}=\mathrm{QuB}_{\mathrm{B}}+\mathrm{Q}_{\mathrm{IS}}
$$

7. Right-ventricular output ( $R V O)$

$$
\mathrm{RVO}=\mathrm{Q}_{\mathrm{LG}}+\mathrm{Q}_{\mathrm{DRL}}
$$

8. Combined ventricular output (CVO)

$$
\mathrm{CVO}=\mathrm{LVO}+\mathrm{RVO}
$$

\section{APPENDIX 2}

Calculations using inferior vena caval + left atrial injections and double withdrawals in the presence of a left-to-right shunt through the ductus arteriosus.

1. Upper body blood flow. The formula is the same as in Appendix 1 except that the isotope is injected in the left atrium rather than in the inferior vena cava.

2. Lower body blood flow. The formula is the same as in Appendix 1 except that the isotope is injected in the left atrium rather than in the inferior vena cava.

3. Right to left shunt through the foramen ovale. Assuming that IVC microspheres that cross the foramen ovale to the left atrium distribute similarly to microspheres injected into the left atrium, then the IVC microspheres recovered in the upper body can be calculated as

$$
\mathrm{S}_{\mathrm{UB}}^{\mathrm{I}}=\mathrm{S}_{\mathrm{FO}}^{\mathrm{i}} \times \mathrm{F}_{\mathrm{UB}}^{\mathrm{L}}
$$

where $S_{U B}^{\prime}$ is the number of IVC microspheres recovered in the upper body, $S_{\text {:o }}^{1}$ is the number of IVC microspheres that cross the foramen ovale, and $\mathrm{F}_{\mathrm{C} \text { B }}^{\mathrm{H}}$ is the fraction of LA microspheres that pass to the upper body. The number of IVC microspheres that cross the foramen ovale is equal to the product of the concentration of microspheres in the IVC injection and the foramen ovale blood flow. That is,

$$
\mathrm{S}_{\mathrm{FO}}^{\mathrm{l}}=\left(\mathrm{S}_{\mathrm{TOT}}^{\mathrm{I}} / \mathrm{Q}_{\mathrm{LB}}\right) \times \mathrm{Q}_{\mathrm{FO}}
$$

where $\left(\mathrm{S}_{\mathrm{TOT}}^{\mathrm{L}} / \mathrm{Q}_{\mathrm{LB}}\right)$ is the concentration of IVC microspheres in the blood that crosses the foramen ovale ( $\mathrm{S}_{\mathrm{TO}}^{\mathrm{T}}$ is the total number of IVC microspheres injected and $\mathrm{Q}_{\mathrm{LB}}$ is the lower body and placental blood flow, which approximates inferior vena caval return) and $\mathrm{Q}_{\mathrm{FO}}$ is the blood flow across the foramen ovale. Substituting equation 2 for $S_{\mathrm{FO}}^{1}$ in equation 1 ,

$$
\begin{array}{ll} 
& \mathrm{S}_{\mathrm{UB}}^{\mathrm{L}}=\left(\mathrm{S}_{\mathrm{TOT}}^{\mathrm{L}} / \mathrm{Q}_{\mathrm{LB}}\right) \times \mathrm{Q}_{\mathrm{FO}} \times \mathrm{F}_{\mathrm{UB}}^{\mathrm{L}} \\
\text { rearranging, } & \mathrm{Q}_{\mathrm{FO}}=\left(\mathrm{S}_{\mathrm{UB}}^{\mathrm{L}} / \mathrm{S}_{\mathrm{TOT}}^{\mathrm{I}}\right) \times \mathrm{Q}_{\mathrm{LB}} / \mathrm{F}_{\mathrm{UB}}^{\mathrm{B}} \\
\text { or } & \mathrm{Q}_{\mathrm{FO}}=\mathrm{Q}_{\mathrm{LB}} \times \mathrm{F}_{\mathrm{UB}}^{\mathrm{l}} / \mathrm{F}_{\mathrm{UB}}^{\mathrm{L}}
\end{array}
$$

where $\mathrm{F}_{\mathrm{UB}}^{\mathrm{l}}$ is $\left(\mathrm{S}_{\mathrm{UB}}^{\mathrm{l}} / \mathrm{S}_{\mathrm{TOT}}^{\mathrm{l}}\right.$ the fraction of IVC microspheres that pass to the upper body.

4. Right to left shunt through the ductus arteriosus. The total number of IVC microspheres recovered in the lower body and placenta is equal the sum of the IVC microspheres ejected by the two ventricles that pass to the lower body and placenta (see Appendix 1, formula 3):

$$
\mathrm{S}_{\mathrm{LB}}^{\mathrm{L}}=\mathrm{S}_{\mathrm{LB}-\mathrm{LV} V}^{\mathrm{L}}+\mathrm{S}_{\mathrm{LB}-\mathrm{RV}}^{\mathrm{L}}
$$

where $S_{\mathrm{LB}-\mathrm{LV}}^{\mathrm{L}}$ are those IVC microspheres that crossed the aortic isthmus, and $\mathrm{S}_{\mathrm{LB}-\mathrm{RV}}^{\mathrm{are}}$ those IVC microspheres that crossed the ductus arteriosus from right to left.

Assuming that IVC microspheres ejected by the left ventricle distribute similarly to LA microspheres ejected by the left ventricle, the ratios of recovered in the upper and lower bodies should be similar. That is,

or

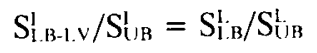

$$
\mathrm{S}_{\mathrm{LB}-\mathrm{L} \mathrm{LV}}^{\mathrm{L}}=\mathrm{S}_{\mathrm{UB}}^{\mathrm{L}} \times \mathrm{S}_{\mathrm{LB}}^{\mathrm{L}} / \mathrm{S}_{\mathrm{UB}}^{\mathrm{L}}
$$

Also, the number of IVC microspheres ejected by the right ventricle and recovered in the lower body and placenta is equal to the product of the concentration of IVC microspheres in the pulmonary arterial reference sample and the blood flow through the ductus arteriosus from right to left (see Appendix 1 , formula 3 ). That is,

$$
\mathrm{S}_{\mathrm{LB}-\mathrm{RV}}^{\mathrm{L}}=\mathrm{Q}_{\mathrm{DRL}} \times \mathrm{C}_{\mathrm{DRL}}
$$

Substituting equations 2 and 3 for $S^{1}{ }_{\text {LB-LV }}$ and $S_{\text {LB-RV }}^{1}$ respectively into equation 1 ,

or

$$
\mathrm{S}_{\mathrm{LB}}^{\mathrm{L}}=\mathrm{S}_{\mathrm{FO}}^{\mathrm{L}} \times\left(\mathrm{S}_{\mathrm{UB}}^{\mathrm{L}} / \mathrm{S}_{\mathrm{UB}}^{\mathrm{L}}\right)+\mathrm{Q}_{\mathrm{DRL}} \times \mathrm{C}_{\mathrm{DRL}}
$$

$$
\mathrm{Q}_{\mathrm{DRL} .}=\left(\mathrm{S}_{\mathrm{UB}}^{\mathrm{L}} \times \mathrm{S}_{\mathrm{LB}}^{\mathrm{L}} / \mathrm{S}_{\mathrm{UB}}^{\mathrm{L}}-\mathrm{S}_{\mathrm{LB}}^{\mathrm{L}}\right) / \mathrm{C}_{\mathrm{DRL}}
$$

The right ventricle receives all IVC microspheres except those that pass through the foramen ovale and ejects all the systemic venous return except that which crosses the foramen ovale. Assuming the microspheres distribute similarly to blood, then the concentration of microspheres in the ductus arteriosus crossing right to left is similar to the concentration in the right ventricle. That is,

$$
\mathrm{C}_{\mathrm{DRL}}=\left(\mathrm{S}_{\mathrm{TOT}}^{\mathrm{l}}-\mathrm{S}_{\mathrm{FO}}^{\mathrm{h}}\right) /\left(\mathrm{QuB}_{\mathrm{U}}+\mathrm{Q}_{\mathrm{LB}}-\mathrm{Q}_{\mathrm{FO}}\right)
$$

where $\left(S_{\mathrm{TOT}}^{1}-\mathrm{S}_{\mathrm{FO}}^{\mathrm{l}}\right.$ ) is the number of IVC microspheres received by the right ventricle and $\left(\mathrm{Q}_{\mathrm{UB}}+\mathrm{Q}_{\mathrm{LB}}-\mathrm{Q}_{\mathrm{FO}}\right)$ is the 
volume of blood ejected by the right ventricle (i.e. all the systemic venous return less the right to left flow through the foramen ovale). Substituting equation 5 for $\mathrm{C}_{\mathrm{DRL}}$ in equation 4 ,

QDRL

$$
=\left(\mathrm{S}_{\mathrm{UB}}^{\mathrm{L}} \times \mathrm{S}_{\mathrm{LB}}^{\mathrm{L}} / \mathrm{S}_{\mathrm{UB}}^{\mathrm{L}}-\mathrm{S}_{\mathrm{LB}}^{\mathrm{L}}\right) /\left(\mathrm{S}_{\mathrm{TOT}}^{\mathrm{I}}-\mathrm{S}_{\mathrm{FO}}^{\mathrm{I}}\right) /\left(\mathrm{Q}_{\mathrm{UB}}+\mathrm{Q}_{\mathrm{LB}}-\mathrm{Q}_{\mathrm{FO}}\right)
$$

5. Left to right shunt through the ductus arteriosus. The blood flow to the lower body and placenta from the left ventricle is equal to all lower body and placental blood flow less the blood flow through the ductus arteriosus from right to left. That is,

$$
\mathrm{Q}_{\mathrm{LV}-\mathrm{LB}}=\mathrm{Q}_{\mathrm{LB}}-\mathrm{Q}_{\mathrm{DRL}}
$$

Assuming that LA microspheres that cross the aortic isthmus distribute similarly to blood (i.e. LA microspheres are well mixed in the aortic isthmus), then

$$
\mathrm{Q}_{\mathrm{LV}-\mathrm{LB}}=\mathrm{Q}_{\mathrm{DLR}} \times \mathrm{S}_{\mathrm{LB}}^{\mathrm{L}} / \mathrm{S}_{\mathrm{LG}}^{\mathrm{L}}
$$

where $Q_{D L R}$ is the left to right shunt through the ductus arteriosus.

Substituting equation 2 for $\mathrm{Q}_{\mathrm{Lv}-\mathrm{I} . \mathrm{B}}$ in equation 1,

and

$$
\mathrm{Q}_{\mathrm{DLR}} \times \mathrm{S}_{\mathrm{LB}}^{\mathrm{L}} / \mathrm{S}_{\mathrm{LG}}^{\mathrm{L}}=\mathrm{Q}_{\mathrm{LB}}-\mathrm{Q}_{\mathrm{DRL}}
$$

$$
\mathrm{Q}_{D L R}=\left(\mathrm{Q}_{\mathrm{LB}}-\mathrm{Q}_{\mathrm{DRL}}\right) /\left(\mathrm{S}_{\mathrm{LB}}^{\mathrm{L}} / \mathrm{S}_{\mathrm{LG}}^{\mathrm{L}}\right)
$$

6. Left ventricular output ( $L V O$ )

$$
\mathrm{LVO}=\mathrm{QUB}_{\mathrm{UB}}+\mathrm{Q}_{\mathrm{DLR}}+\mathrm{Q}_{\mathrm{LB}}-\mathrm{Q}_{\mathrm{DRL}}
$$

7. Right ventricular output ( $R V O)$

$$
\mathrm{RVO}=\mathrm{Q}_{\mathrm{LB}}+\mathrm{Q}_{\mathrm{UB}}-\mathrm{Q}_{\mathrm{FO}}
$$

8. Combined ventricular output ( $\mathrm{CVO}$ )

$$
\mathrm{CVO}=\mathrm{LVO}+\mathrm{RVO}
$$

9. Pulmonary blood flow

$$
\mathrm{Q}_{\mathrm{LG}}=\mathrm{CVO}-\mathrm{Q}_{\mathrm{LB}}-\mathrm{Q}_{\mathrm{UB}}
$$

